\title{
Antiallodynic and antihyperalgesic activities of zerumbone via the suppression of IL-I $\beta$, IL-6, and TNF- $\alpha$ in a mouse model of neuropathic pain
}

This article was published in the following Dove Press journal:

Journal of Pain Research

8 November 2017

Number of times this article has been viewed

\author{
Banulata Gopalsamy \\ Ahmad Akira Omar Farouk \\ Tengku Azam Shah Tengku \\ Mohamad \\ Mohd Roslan Sulaiman \\ Enoch Kumar Perimal \\ Department of Biomedical Sciences, \\ Faculty of Medicine and Health \\ Sciences, Universiti Putra Malaysia, \\ Serdang, Selangor, Malaysia
}

Background: Neuropathic pain is a debilitating condition that severely affects the quality of life for those with this pain condition, and treatment for pain relief is greatly sought-after. Zerumbone (Zer), a sesquiterpene compound isolated from the rhizomes of a Southeast Asian ginger plant, Zingiber zerumbet (L.) Roscoe ex Smith. (Zingiberaceae), showed antinociceptive and antiinflammatory properties when previously tested on models of nociception and inflammation. Objective: This study investigated the effects of prophylactic administration of zerumbone on allodynia and hyperalgesia in a mouse model of chronic constriction injury (CCI)-induced neuropathic pain.

Methods: Intraperitoneal administration of Zer $(5-50 \mathrm{mg} / \mathrm{kg})$ from day 1 post-surgery was carried out to identify the onset and progression of the pain condition. Responses toward mechanical and cold allodynia, and mechanical and thermal hyperalgesia were assessed on days 3, 5, 7, 9, 11 , and 14 post-surgery. Blood plasma and spinal cord levels of interleukin (IL)-1 $\beta$, IL-6, tumor necrosis factor- $\alpha$, and IL-10 were screened using enzyme-linked immunosorbent assay on day 15. Results: Zer (10 and $50 \mathrm{mg} / \mathrm{kg}$ ) attenuated pain symptoms on all days of behavioral testing without any signs of sedation in the rotarod test. $\mathrm{ED}_{50}$ values for mechanical allodynia, cold allodynia, thermal hyperalgesia, and mechanical hyperalgesia were 9.25, 9.507, 8.289, and 9.801 $\mathrm{mg} / \mathrm{kg}$, respectively. Blood plasma and spinal levels of IL-1 $\beta$, IL-6, and tumor necrosis factor- $\alpha$ but not IL-10 were significantly $(p<0.05)$ suppressed by zer treatment.

Discussion and conclusion: Zer exhibits its antiallodynic and antihyperalgesic properties via reduced sensitization at nociceptor neurons possibly through the suppression of inflammatory mediators. Zer may prove to be a novel and beneficial alternative for the management of neuropathic pain.

Keywords: zerumbone, allodynia, hyperalgesia, interleukin- $1 \beta$, interleukin 6 , tumor necrosis factor- $\alpha$

\section{Introduction}

Neuropathic pain is a highly prevalent global problem that affects almost $6.9 \%-10 \%$ of the population worldwide. ${ }^{1}$ Approximately $40 \%$ of patients attending pain clinics for treatment of various forms of pain conditions exhibit neuropathic symptoms. ${ }^{2,3}$ Neuropathic pain arises due to factors that cause direct trauma to the nerve, tumour growth, cancer compression, and cancer therapy. ${ }^{4}$ Apart from autoimmune diseases and metabolic diseases such as diabetes, lifestyle of individuals such as smoking and alcoholism could also lead to this condition. ${ }^{5,6}$

Neuropathic pain is defined as "pain that arises as a direct consequence of a lesion or diseases affecting the somatosensory system" and is often accompanied by symptoms
Correspondence: Enoch Kumar Perimal Department of Biomedical Sciences, Faculty of Medicine and Health Sciences, Universiti Putra Malaysia, 43400 Serdang, Selangor, Malaysia

Tel +603 89472774

Fax +60389472774

Email enoch@upm.edu.my 
of allodynia and hyperalgesia. ${ }^{7}$ This debilitating pain condition severely affects the physical activities of patients and further leads to emotional distress. ${ }^{8}$ As currently available conventional drugs are only partially effective, accompanied with undesired side effects, alternative pain management options are greatly sought-after., ${ }^{910}$

The pathophysiology of neuropathic pain shows that inflammation is a vital component of the progression and maintenance of this condition. ${ }^{11}$ When a nerve is injured, Wallerian degeneration takes place whereby axons and myelin sheaths undergo degradation. The vascular permeability is compromised, permitting infiltration of macrophages and various other immune cells such as mast cells to the injury site. Inflammatory cytokines, principally interleukin (IL)-1 $\beta$, tumor necrosis factor (TNF)- $\alpha$, and IL-6, are secreted by resident and non-resident macrophages. ${ }^{12,13}$ Inflammatory mediators are signaling proteins that take up a role as intercellular messengers as an immune response. ${ }^{14}$ They in turn recruit and activate macrophages, neutrophils, and surrounding glial cells at the site of injury. ${ }^{14}$ Primary afferent neurons are directly sensitized by TNF- $\alpha$, IL- $1 \beta$, and IL- 6 via their receptors. ${ }^{15-17}$

Inflammatory cytokines have a primary role that triggers the downstream cascade of the inflammatory process, followed by the antiinflammatory process during the recovery and repair process. An "inflammatory soup" is formed comprising adenosine triphosphate, bradykinin, histamine, serotonin, prostaglandin $\mathrm{E}_{2}$, leukotriene $\mathrm{B}$, nerve growth factor, substance $\mathrm{P}$, and calcitonin gene-related peptide contributing to neurogenic inflammation. ${ }^{18}$ Peripheral sensitization occurs, a result of which normally inactive and unresponsive "silent nociceptors" become sensitive to the development of spontaneous discharges, giving rise to allodynia. ${ }^{19,20}$ In addition, nociceptors, which usually transmit painful stimulus, are now hypersensitive and thus exhibit an exaggerated pain response, also known as hyperalgesia. ${ }^{19}$

Considering that neuropathic pain is largely modulated and maintained by the neuroimmune and neuroinflammatory activities, treatments or drugs often target to either reverse or reduce the inflammatory process. ${ }^{21}$ We have recently reported that zerumbone (Zer) (Figure 1), a monocyclic, sesquiterpenoid phytochemical substance isolated from the rhizome oil of Zingiber zerumbet (L.) Roscoe ex Smith (Zingiberaceae), was able to therapeutically attenuate symptoms of neuropathic pain. ${ }^{22}$ More recently, we have elucidated the involvement of the serotonergic and L-Arginine-Nitric Oxide-cGMP-K ${ }^{+}$ATP channel pathways in the analgesic action of Zer in neuropathic pain. ${ }^{23,24}$ This

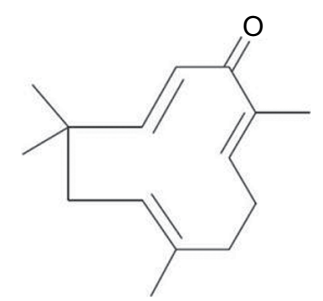

Figure I Chemical structure of zerumbone.

reinforces that Zer is a potential bioactive compound for the management of neuropathic pain.

Apart from its antinociceptive properties, Zer has also been widely reported for its antiinflammatory properties. ${ }^{25-27}$ Zerumbone successfully reversed the increase in IL-1, IL- 6 , and TNF- $\alpha$ production in the inflammatory response of diabetic rats. ${ }^{28}$ Furthermore, zerumbone suppresses the synthesis of these inflammatory mediators in dextran sodium sulfate-induced colitis of mice. ${ }^{29}$ Direct influence of zerumbone, specifically, on these aforementioned mediators has been well documented, not just in various other in vivo models but also in vitro. ${ }^{30}$ However, suppression of the inflammatory process by zerumbone in a neuropathic pain model, specifically in the chronic constriction injury (CCI) model, is generally lacking and remains to be explored.

With this in mind, our study explored, for the first time, the prophylactic effects of Zer treatment administered from the initial stage throughout the progression stage of this neuropathic pain condition. We also provide evidence of the inflammatory components in the circulation as well as in spinal cord tissues following treatment with this compound. This approach with a prophylactic paradigm is expected to reverse the neuroimmune and neuroinflammatory processes. The significance of such treatments in clinical settings is that it serves as a preventive measure that could be started in advance for patients with higher risk of developing neuropathic pain, with the hope to delay or lessen the advancement of the condition.

\section{Materials and methods}

\section{Zerumbone extraction and isolation}

Zerumbone was prepared from rhizomes of Zingiber zerumbet using the same protocol as previously described by Perimal et al. ${ }^{26}$ The plant was identified and confirmed by a botanist and a specimen was inserted at Institute of Bioscience, Universiti Putra Malaysia (Reference number: SK622/07). Briefly, rhizomes of Zingiber zerumbet were purchased from Chow Kit wet market, washed and sliced 
into small pieces of $\sim 0.5-1 \mathrm{~mm}$ in size. The hydrodistillation process was carried out by placing the rhizome slices in the round bottom flask with water added to it. Soluble oils were collected in a vial $4 \mathrm{~h}$ after water and hexane were added to it. After the separation of the hexane and water, the water phase was removed. The crude essential oil was obtained from the hexane phase using a rotary evaporator before being placed at $4^{\circ} \mathrm{C}$ for $48 \mathrm{~h}$. Only the pure crystallized product of the compound was subjected to column chromatography. The yield was $0.07 \%$. The purity was determined by subjecting the eluate to thin-layer chromatography. This was followed by recrystallization before the compound was analyzed with high-performance liquid chromatography (HPLC) where the purity was determined to be more than $98 \%$. Zerumbone was dissolved in Tween-20, dimethyl sulfoxide (DMSO), and physiological saline $0.9 \%$ at a ratio of 5:5:90 and was prepared freshly just before the experiments.

\section{Animals}

Male ICR mice (25-35 $\mathrm{g}$ at the beginning of the experiments) were housed eight mice per cage under a $12 \mathrm{~h}$ dark/light cycle at a room temperature of $24^{\circ} \mathrm{C} \pm 2{ }^{\circ} \mathrm{C}$ and a humidity level of $70 \%$, with free access to water and standard laboratory chow. Mice were acclimatized for 1 week prior to any experimental procedures. All animal experiments were performed in accordance to the ethical guidelines for investigation of experimental pain in conscious animals. All procedures were approved by the Institutional Animal Care and Use Committee (IACUC) of Universiti Putra Malaysia (Reference number: UPM/IACUC/AUP-R060/2013).

\section{Chemicals}

Tween-20, DMSO, amitriptyline, and morphine sulfate were purchased from Sigma-Aldrich Chemical Co. (St. Louis, MO, USA). Morphine was dissolved in $0.9 \%$ normal saline. All treatments were administered intraperitoneally (ip) at a volume of $10 \mathrm{~mL} / \mathrm{kg}$.

\section{Preselection of mice and body weights}

Mice were preselected with rotarod (UgoBasile, Varese, Italy) spinning at $20 \mathrm{rpm}$ and only mice that were able to remain on the wheels for $120 \mathrm{~s}$ without falling or rolling over were used in the experiment to eliminate possible occurrence of motor dysfunction. Mice with approximately similar body weights were preselected to be used in the experiment and the weights were measured daily throughout the experimental period to monitor the effect of treatments on their feeding habits and general well-being.

\section{Experimental design}

A total of 56 mice were allocated into 7 groups $(n=8$ mice per group) as follows:

1. Sham

2. $\mathrm{CCI}+$ vehicle

3. $\mathrm{CCI}+\operatorname{Zer}(5 \mathrm{mg} / \mathrm{kg}$ ip $)$

4. $\mathrm{CCI}+\operatorname{Zer}(10 \mathrm{mg} / \mathrm{kg}$ ip $)$

5. $\mathrm{CCI}+\operatorname{Zer}(50 \mathrm{mg} / \mathrm{kg}$ ip$)$

6. CCI + morphine $(1 \mathrm{mg} / \mathrm{kg}$ ip $)$

7. CCI + amitriptyline $(20 \mathrm{mg} / \mathrm{kg}$ ip $)$

Administration of drugs started $24 \mathrm{~h}$ post-surgery according to their respective groups and dosages. Drugs were given once a day for 14 days as described by Guneli et al. ${ }^{42}$

\section{$\mathrm{CCl}$ surgery}

The procedure of Bennett and $\mathrm{Xie}^{31}$ was adapted with minor modifications to induce neuropathy. ${ }^{32,33}$ Briefly, mice were anesthetized with tribromoethanol (250 mg/kg ip) before an incision was made to the skin to expose the left common sciatic nerve. Three loose ligations with $1 \mathrm{~mm}$ spacing between ligatures were made using $4 / 0$ silk sutures. A brief twitch in the left hind limb marks the tightness of the ligatures. The skin incision was closed using a non-absorbable suture, before iodine was applied to the area. The entire surgery procedure was carried out on mice in the sham group but with no ligations made to the sciatic nerve to confirm the consequence of nerve injury.

\section{Nociceptive assay}

Responses toward mechanical allodynia, cold allodynia, thermal hyperalgesia, and mechanical hyperalgesia were evaluated using von Frey, cold plate, Hargreaves, and Randall-Selitto tests, respectively. Baseline measurements of the nociceptive assays were obtained 1 day before CCI surgery (pre-CCI). Nociceptive assays were carried out 30 min following drug administration on days $3,5,7,9,11$, and 14. The assays were carried out in a sequence of testing for mechanical allodynia, cold allodynia, thermal hyperalgesia, and mechanical hyperalgesia whereby this sequence was consistent throughout the experiment.

\section{von Frey filament test}

Response toward mechanical allodynia was evaluated by von Frey filament test as described by Chaplan et $\mathrm{al}^{34}$ and Campana and Rimondini. ${ }^{35}$ Mice were placed in a Plexiglass chamber on an elevated wire mesh grid and were allowed to acclimate prior to testing. When all explorative and grooming 
behavior was reduced and the animal is on its four limbs, von Frey filament (IITC Life Science Inc., Woodland Hills, CA, USA) was applied to the middle of the dorsum of the ipsilateral paw followed by the contralateral paw. The mean of three readings was recorded as the withdrawal threshold.

\section{Cold plate test}

Response toward cold allodynia was evaluated by cold plate test as described by Nadal et al. ${ }^{36}$ Mice were placed onto a cold plate (UgoBasile, Varese, Italy) at a temperature of $5^{\circ} \mathrm{C} \pm 0.2^{\circ} \mathrm{C}$. The number of times the mouse lifted, scratched, or flinched its paws were counted as the number of paw lifts. Each mouse was observed for a total of $5 \mathrm{~min}$ and measurements were obtained from both the ipsilateral and contralateral paws. The total number of lifts of the ipsilateral paw was then subtracted from the total number of lifts of the contralateral paws.

\section{Hargreaves test}

Response toward thermal hyperalgesia was assessed using Hargreaves test as described by Hargreaves et $\mathrm{al}^{37}$ using Hargreaves apparatus (Model 37370, Gemonio, Varese, Italy). Mice were placed in a Plexiglass chamber which was placed on an elevated clear platform. Following a brief acclimatization period, a radiant heat source with an infrared radiation intensity of $80 \mathrm{~W} / \mathrm{sr}$ was directed to the mid-plantar surface of its ipsilateral paw followed by the contralateral paw. The time taken for the mouse to either remove or flinch its paw was recorded as the withdrawal latency. The radiant heat source was removed after $20 \mathrm{~s}$ to prevent injury to the paws.

\section{Randall-Selitto}

Mice response toward mechanical hyperalgesia was carried out as previously described by Randall and Selitto. ${ }^{38}$ Briefly, mice were restrained as such where they were able to flex their legs. A constantly increasing pressure was applied to the plantar surface of both the ipsilateral and contralateral hind paws through the tip of the paw pressure meter (IITC Life Science Inc., Woodland Hills, CA, USA). Readings were obtained when the mice attempted to withdraw the paw. The cut-off force was set at $200 \mathrm{~g}$ to prevent further injury to the paws.

\section{Determination of $\mathrm{ED}_{50}$ values}

The effective dose $\left(\mathrm{ED}_{50}\right)$ was determined for each nociceptive assay using GraphPad Prism V.5. The doses were $\log [$ dose $]$ transformed and plotted against $\%$ of inhibition. A nonlinear regression (curve fit) was generated to determine the $\mathrm{ED}_{50}$ values.

\section{Motor coordination}

Possible sedative effects of the drug treatments were evaluated by the rotarod test (UgoBasile, Varese, Italy) as previously described by Zulazmi et al. ${ }^{24}$ On day 14 post-CCI, mice were administered with their respective treatments. Exactly 30 min later, the animals were placed on the rotarod bar rotating at $20 \mathrm{rpm}$. The time spent on the bar for a period of up to $180 \mathrm{~s}$ was recorded. This method was carried out only in sham-operated and CCI mice treated with vehicle, Zer $(50 \mathrm{mg} / \mathrm{kg})$, morphine $(1 \mathrm{mg} / \mathrm{kg})$, and amitriptyline (20 mg/kg).

\section{Euthanasia and organ collection}

On day 15 post-CCI, treatments were given accordingly and mice were sacrificed 30 min posttreatment. Blood was withdrawn via cardiac puncture, centrifuged at $3000 \mathrm{~g}$ at $4^{\circ} \mathrm{C}$ and frozen at $-20^{\circ} \mathrm{C}$ until assayed. The spinal cord at the lumbar 4-6 region was dissected out and homogenized using a Polytron device (Mississauga, Ont, Canada). Approximately, $750 \mu \mathrm{L}$ PBS per $25 \mathrm{mg}$ tissue was used to homogenize the tissues before samples were centrifuged for $10 \mathrm{~min}$ at $4^{\circ} \mathrm{C}$ at $12,000 \mathrm{~g}$. The aliquot of the supernatant fraction was stored at $-20^{\circ} \mathrm{C}$ until further use.

\section{Enzyme-linked immunosorbent assay}

Blood plasma and spinal cord cytokines (TNF- $\alpha$, IL-1 $\beta$, IL-10, and IL-6) levels were measured using mouse-specific, enzyme-linked immunosorbent assay (ELISA) kits purchased from eBioscience, Vienna, Austria. Assays were performed according to the manufacturer's instructions. The samples were assayed in duplicates and the cytokines levels were expressed in $\mathrm{pg} / \mathrm{mg}$ whereby $50 \mu \mathrm{L}$ of blood plasma or tissue protein was used for each assay. Standards were run in every trial, and standard curves were generated for every assay. Sample concentrations were calculated using Bio-Plex Manager software.

\section{Statistical analysis}

All data obtained were checked for normality using Shapiro-Wilk Test for Normality before statistical testing was carried out. Data for behavioral testing were expressed as mean \pm SEM and were analyzed using two-way ANOVA followed by Bonferroni's post hoc analysis. Values for ELISA were expressed relative to the total protein. A confidence interval of $5 \%$ or less was considered to be statistically significant. All behavioral tests and ELISA assays were carried out where the investigator was blinded from the treatment group of the animals. 


\section{Results \\ von Frey filament test}

Figure 2 represents the mean body weights of mice throughout the experiment. Mice with similar $(\mathrm{F}(6,49)=3.966, p=0.003)$ at the beginning of the experiment showed no significant ( $p>0.05$ ) changes between experimental groups on all days.

Figure 3 represents the pain response toward mechanical allodynia when tested with von Frey filaments. Mice that underwent CCI surgery show significantly increased sensitivity as early as day $3(\mathrm{~F}(6,49)=14.121, p=0.000)$ and were significantly different $(p \leq 0.05)$ from sham group throughout the experimental period. Treatment with Zer at a dose of $5 \mathrm{mg} / \mathrm{kg}$ did not show significant $(p>0.05)$ difference from the vehicle group, indicating the lack of effect of this treatment dose on mechanical allodynia. However, Zer administered at higher doses of 10 and $50 \mathrm{mg} / \mathrm{kg}$ ip significantly attenuated mechanical allodynia as the values were significantly different from the vehicle group on all days of testing. Both morphine, $1 \mathrm{mg} / \mathrm{kg}$ ip, and amitriptyline, $20 \mathrm{mg} / \mathrm{kg}$ ip, that serve as positive controls, completely alleviated mechanical allodynia and showed mean values similar $(p>0.05)$ to that of the sham group. The withdrawal threshold mean values of the contralateral paws were not affected by either the surgery or the treatments as the values were not significantly different from the sham group (F $(6$, 49) $=1.479, p=0.209)$.

\section{Cold plate test}

Figure 4 shows the response cold allodynia which was tested using the cold plate test. All mice did not show any paw lifting in the baseline data $(0.00 \pm 0.00)(F(6,49)=0.000$; $p=0.00$ ). Following CCI and treatment with vehicle, the mean number of paw lifting was recorded to be $16.29 \pm 0.71$ on day 14. Again, a significant $(p<0.05)$ effect was observed only in Zer 10 and $50 \mathrm{mg} / \mathrm{kg}$ ip with mean values $6.43 \pm 0.90$ and $2.86 \pm 0.53$, respectively. Even though both positive control drugs alleviated $(p<0.05)$ cold allodynia, amitriptyline, $20 \mathrm{mg} / \mathrm{kg}$ ip was more effective with a mean value of $0.29 \pm 0.18$ on day 14 . Cold allodynia was not observed in the contralateral paws.

\section{Hargreaves test}

The CCI model produced thermal hyperalgesia as significant increased pain response was observed in CCI groups compared to the sham group $(\mathrm{F}(6,49)=6.128, p=0.000)$ as shown in Figure 5. Zerumbone at doses of 10 and $50 \mathrm{mg} / \mathrm{kg}$ ip alleviated thermal hyperalgesia on all days of behavioral testing. Both these doses showed similar $(p>0.05)$ effect to morphine on days 9,11 , and 14 . Amitriptyline completely reversed thermal hyperalgesia as the values were not significantly different $(p>0.05)$ from the sham group. Thermal hyperalgesia was absent in the contralateral paws.

\section{Randall-Selitto test}

CCI surgery successfully developed mechanical hyperalgesia (Figure 6) as all groups subjected to CCI showed reduced threshold compared to sham-operated mice. Response toward mechanical hyperalgesia was significantly lowered $(\mathrm{F}(6,49)=55.731 ; p=0.000)$ in higher doses of Zer (10 and $50 \mathrm{mg} / \mathrm{kg})$, morphine (1 mg/kg ip), and amitriptyline (20 $\mathrm{mg} / \mathrm{kg}$ ip) treated groups indicating the antihyperalgesic property of Zer and the positive control drugs. Lower dose

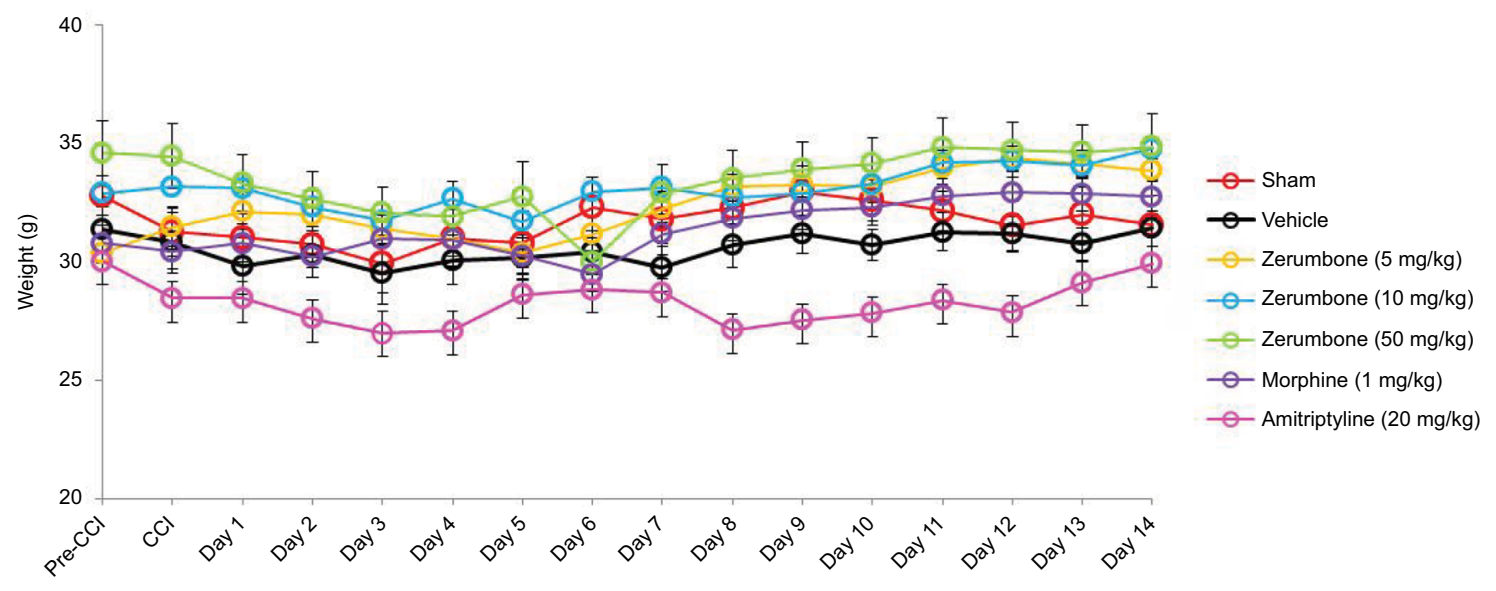

Figure 2 Changes in the body weights of mice in different treatment groups throughout the experimental period of I4 days.

Notes: Data are expressed as mean \pm SEM; $n=8$ mice per group, assessed by two-way ANOVA followed by Bonferroni's post hoc analysis. Filled circles indicate data significantly different $(p \leq 0.05)$ from vehicle-treated group.

Abbreviations: ANOVA, analysis of variance; $\mathrm{CCl}$, chronic constriction injury. 

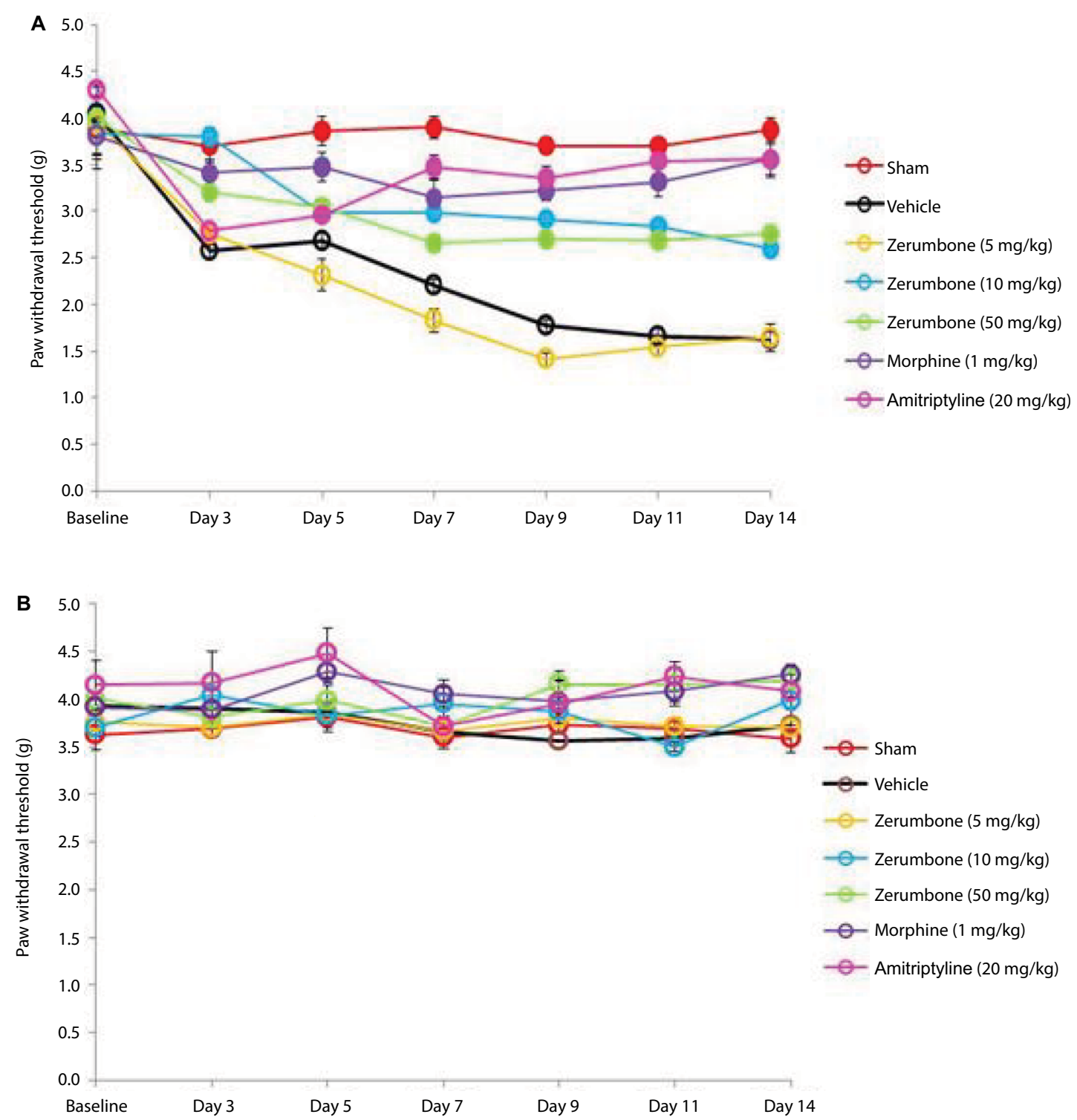

Figure 3 Effect of treatments on the (A) ipsilateral and (B) contralateral paw withdrawal thresholds toward mechanical allodynia as tested with von Frey filament test. Notes: Data are expressed as mean \pm SEM; $n=8$ mice per group, assessed by two-way ANOVA followed by Bonferroni's post hoc analysis. Filled circles indicate data significantly different $(p \leq 0.05)$ from vehicle-treated group.

Abbreviation: ANOVA, analysis of variance.

of Zer ( $5 \mathrm{mg} / \mathrm{kg})$, however, failed to exhibit antihyperalgesic effect as the threshold values were not significantly different $(p>0.05)$ from the vehicle group. On the contralateral paw, mechanical hyperalgesia was absent and was not affected by the treatments.

\section{Motor coordination test}

Rotarod test was used to evaluate the presence of sedative effects of the treatments (Figure 7). Neither vehicle nor the highest dose of Zer (50 mg/kg ip), morphine (1 mg/kg ip), or amitriptyline $(20 \mathrm{mg} / \mathrm{kg}$ ip) showed reduced effect, as all mice were able to complete the entire rotarod session, which lasted for $3 \mathrm{~min}$.

\section{Enzyme-linked immunosorbent assay Blood plasma}

Figure 8 shows the circulating levels of inflammatory mediators in the CCI model and after the treatment of Zer (10 and $50 \mathrm{mg} / \mathrm{kg}$ ). CCI caused an increase in pro-inflammatory cytokines, precisely IL-1 $\beta$, TNF- $\alpha$, and IL-6. Zerumbone treatment successfully reduced IL- $1 \beta$, TNF- $\alpha$, and IL-6 compared to the vehicle group. The levels IL- $\beta$ and TNF- $\alpha$ 


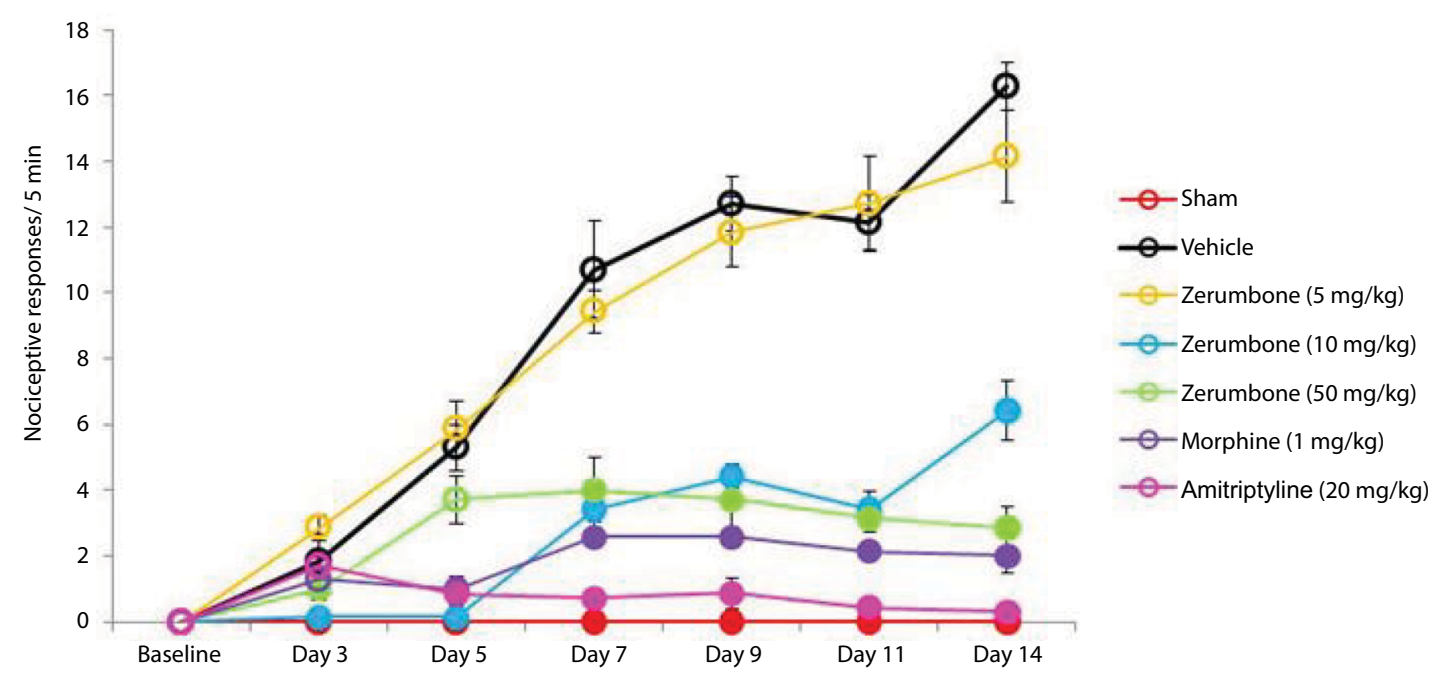

Figure 4 Effect of treatments on cold allodynia withdrawal response as tested with cold plate.

Notes: Data are expressed as mean \pm SEM; $n=8$ mice per group, assessed by two-way ANOVA followed by Bonferroni's post hoc analysis. Filled circles indicate data significantly different $(p \leq 0.05)$ from vehicle-treated group.

Abbreviation: ANOVA, analysis of variance.

were reduced to similar levels $(p>0.05)$ of the sham group but IL-6 level was significantly higher $(p \leq 0.05)$ than the sham group. The differences in the blood level of inflammatory mediators were not significantly different in both doses of Zer $(10$ and $50 \mathrm{mg} / \mathrm{kg}$ ). However, blood plasma IL-10 showed no significant difference $(p>0.05)$ in all the groups tested, indicating that neither the CCI surgery nor Zer treatments altered the levels.

\section{Lumbar region of the spinal cord}

Figure 9 represents the levels of inflammatory mediators in the lumbar 4-6 of spinal cord following CCI and treatment with Zer (10 and $50 \mathrm{mg} / \mathrm{kg}$ ). The levels showed similar trend with the blood levels of inflammatory mediators where IL-1 $\beta$, TNF- $\alpha$, and IL- 6 were reduced $(p \leq 0.05)$ with Zer treatment but no changes $(p>0.05)$ in IL-10 level was detected. Interleukin-6 level was significantly higher $(p \leq 0.05)$ than its sham counterpart. Higher dose of zerumbone $(50 \mathrm{mg} / \mathrm{kg})$ was not able to exhibit a significant difference $(p>0.05)$ from the lower dose of Zer $(10 \mathrm{mg} / \mathrm{kg})$ used in the assays.

\section{Discussion}

This study aimed to highlight the effects of prophylactic treatment of Zer at three different doses on attenuation of allodynia and hyperalgesia as well as the changes in production of inflammatory mediators. The outcome showed that all the drugs used as treatment did not cause any form of discomfort, change in appetite, or inability to access food throughout the period of 14 days as the body weights did not undergo any drastic changes. Hyperalgesia and allodynia were observed as early as our first day of behavioral testing on day 3 possibly due to the axon degeneration process that occurs from 24 to $48 \mathrm{~h}$ in mice. ${ }^{39}$ Zerumbone successfully exerted analgesia at doses of 10 and $50 \mathrm{mg} / \mathrm{kg}$ but not 5 $\mathrm{mg} / \mathrm{kg}$ throughout the experimental period. This outcome is consistent with our earlier study by Zulazmi et al. ${ }^{22}$ This indicates that Zer treatment, both therapeutically and prophylactically, resulted in similar outcomes.

Morphine, the "gold standard" drug for pain treatment, and amitriptyline, a first-line drug for neuropathic pain treatment, were used as positive controls in this study. Even though these drugs were very effective in the attenuation of allodynia and hyperalgesia, reversing the threshold/ latency similar to that of the sham group, Zer (10 and 50 $\mathrm{mg} / \mathrm{kg}$ ) was comparable with these drugs at some points. Most importantly, the effects of all the drugs were validated to be behavior specific since mice receiving the highest dose of drugs were able to maintain their balance on the rotarod throughout the $180 \mathrm{~s}$ time period. This ruled out the possibilities that the reduced pain response is due to suppression of general behavior as a result of the sedative effects of the drugs. ${ }^{40}$ The $\mathrm{ED}_{50}$ values of Zer were calculated to be $9.245 \mathrm{mg} / \mathrm{kg}\left(\mathrm{R}^{2}=0.9894\right), 9.507 \mathrm{mg} / \mathrm{kg}\left(\mathrm{R}^{2}=0.9794\right)$, $8.289 \mathrm{mg} / \mathrm{kg}\left(\mathrm{R}^{2}=0.9105\right)$, and $9.801 \mathrm{mg} / \mathrm{kg}\left(\mathrm{R}^{2}=0.9157\right)$ for mechanical allodynia, cold allodynia, thermal hyperalgesia, and mechanical hyperalgesia, respectively. Therefore, the best dose for prophylactic Zer treatment is $10 \mathrm{mg} / \mathrm{kg}$. 
A
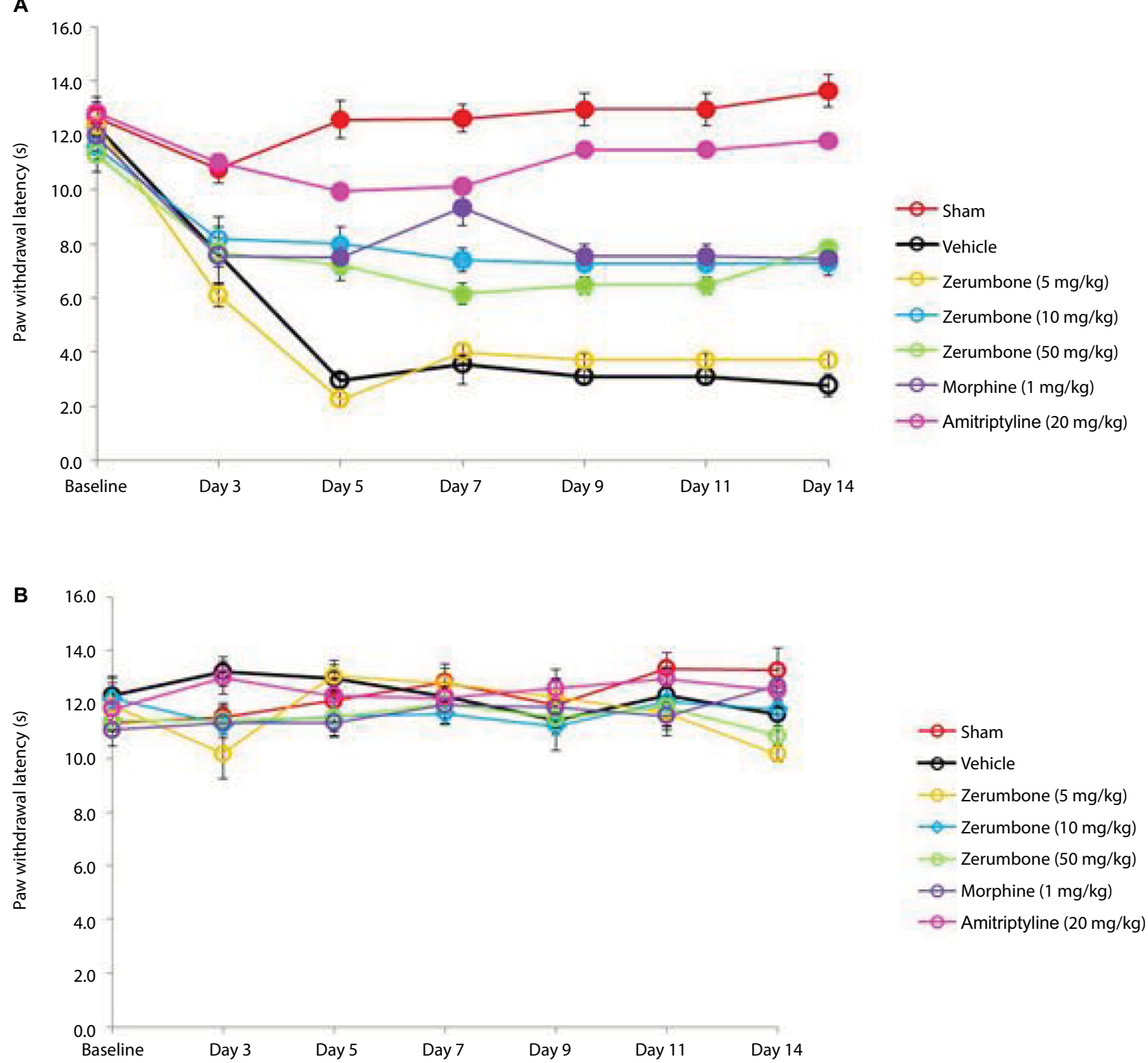

Figure 5 Effect of treatments on the (A) ipsilateral and (B) contralateral paw withdrawal latency toward thermal hyperalgesia as tested with Hargreaves.

Notes: Data are expressed as mean \pm SEM; $n=8$ mice per group, assessed by two-way ANOVA followed by Bonferroni's post hoc analysis. Filled circles indicate data significantly different $(p \leq 0.05)$ from vehicle-treated group.

Abbreviation: ANOVA, analysis of variance.

We carried out this study on the CCI model of neuropathic pain as it involves both components of nerve injury and inflammation. ${ }^{41}$ The results showed that the CCI model induced upregulation of plasma and spinal cord IL-1 $\beta$, TNF- $\alpha$, and IL- 6 observed in the vehicle group on day 14 , in line with previous studies. ${ }^{41-43}$ IL-1, TNF- $\alpha$, and IL-6 are expressed as early as the second or third day post injury, during the first phase of Wallerian degeneration process. IL- $1 \beta$ reached maximum levels after $24 \mathrm{~h}$ of nerve injury and again showed peak production on day $14 .{ }^{44}$ Within hours of nerve injury, mRNA coding of TNF- $\alpha$ and TNF receptors were rapidly increased in the sciatic nerve and subsequently within 1-3 days in the dorsal root ganglion (DRG), with the elevated levels displayed for at least 2 weeks post-injury. ${ }^{45,46}$

The action of Zer in pain modulation could take place at different levels of the pain pathway which include nerve terminals, DRG, spinal cord, and the ascending or descending tracts to the supraspinal regions. Furthermore, Zer could also act on various ion channels that are present along the peripheral nerves. In this study, Zer treatment suppresses inflammatory mediators, lowering pain transmission from primary afferent neurons to the ascending tract of the pain pathway. Pain impulses reaching the supraspinal regions will be modulated, and thus lower pain levels are perceived. 


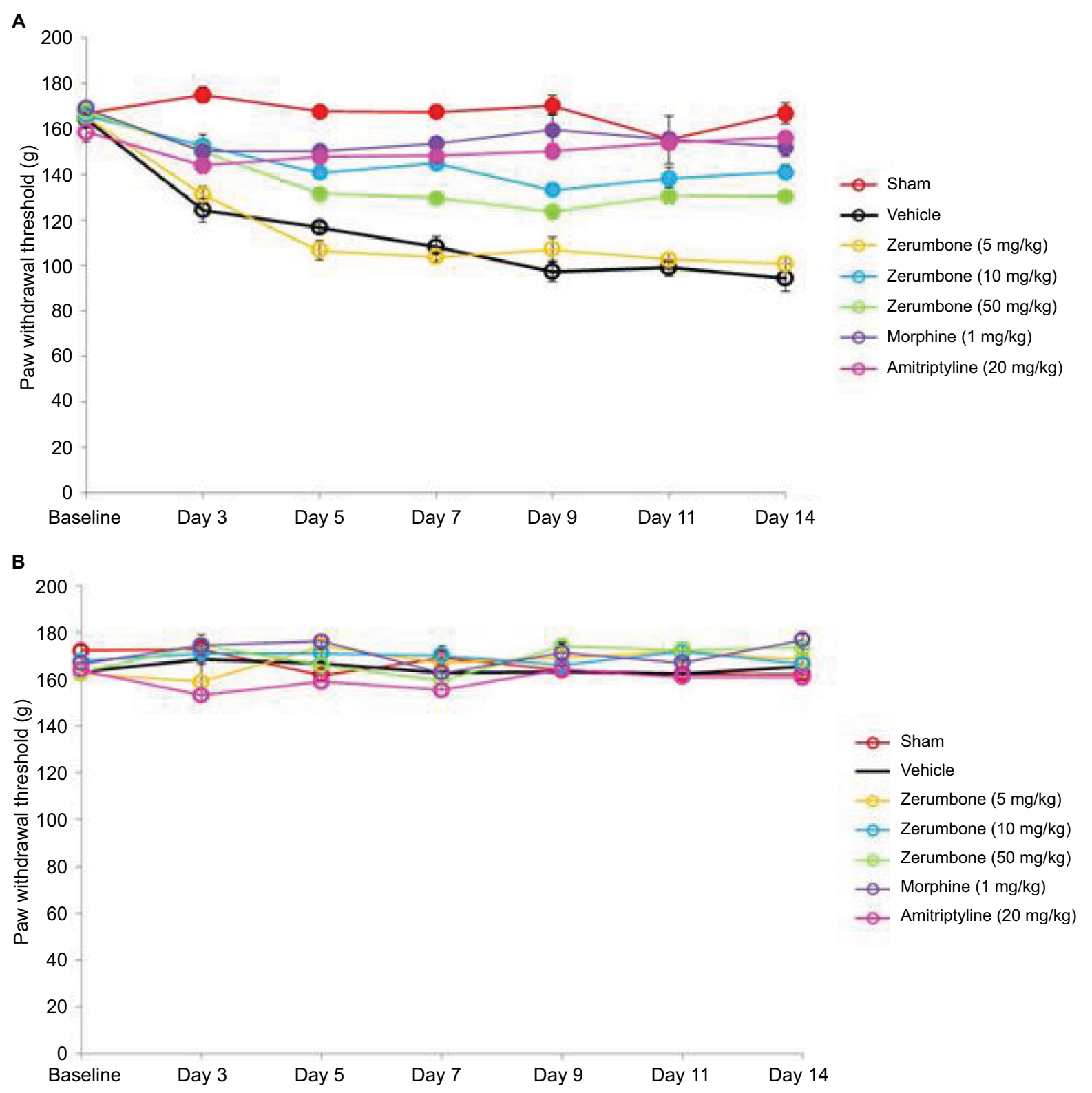

Figure 6 Effect of treatments on the (A) ipsilateral and (B) contralateral paw withdrawal threshold toward mechanical hyperalgesia as tested with Randall-Selitto in CCI and sham mice.

Notes: Data are expressed as mean \pm SEM; $n=8$ mice per group, assessed by two-way ANOVA followed by Bonferroni's post hoc analysis. Filled circles indicate data significantly different $(p \leq 0.05)$ from vehicle-treated group.

Abbreviations: ANOVA, analysis of variance; $\mathrm{CCl}$, chronic constriction injury.

This is then translated as lowered pain response that we have observed in our behavioral study.

The role of IL-6 in the pathogenesis of neuropathic pain has also been reported. In a sciatic cryoneurolysis (SCN) rat model where nerve injury is induced by freezing the sciatic nerve, elevated IL-6-like immunoreactivity and IL-6 mRNA were observed in the spinal cord dorsal and ventral horns of the rats. ${ }^{47,48}$ Furthermore, administration of human IL-6 intrathecally could also mimic and cause pain behavior after SCN ${ }^{47}$ The levels of IL- $1 \beta$ and TNF- $\alpha$ are also elevated in the DRG and spinal cord following peripheral nerve injury. Glial cells, principally astrocytes and microglia that are present within the dorsal horn, are activated to play essential roles in pain transmission and maintenance of this chronic disease. ${ }^{12,49}$ These glial cells secrete IL-1 $\beta$, IL- 6 , and TNF- $\alpha$ which are characterized as messengers of the immune system to act on various cells, including neurons. ${ }^{49}$

Since pro-inflammatory cytokines are critical in the initiation and maintenance of neuropathic pain, antagonism of these cytokines' signaling inhibits neuronal hypersensitivity 


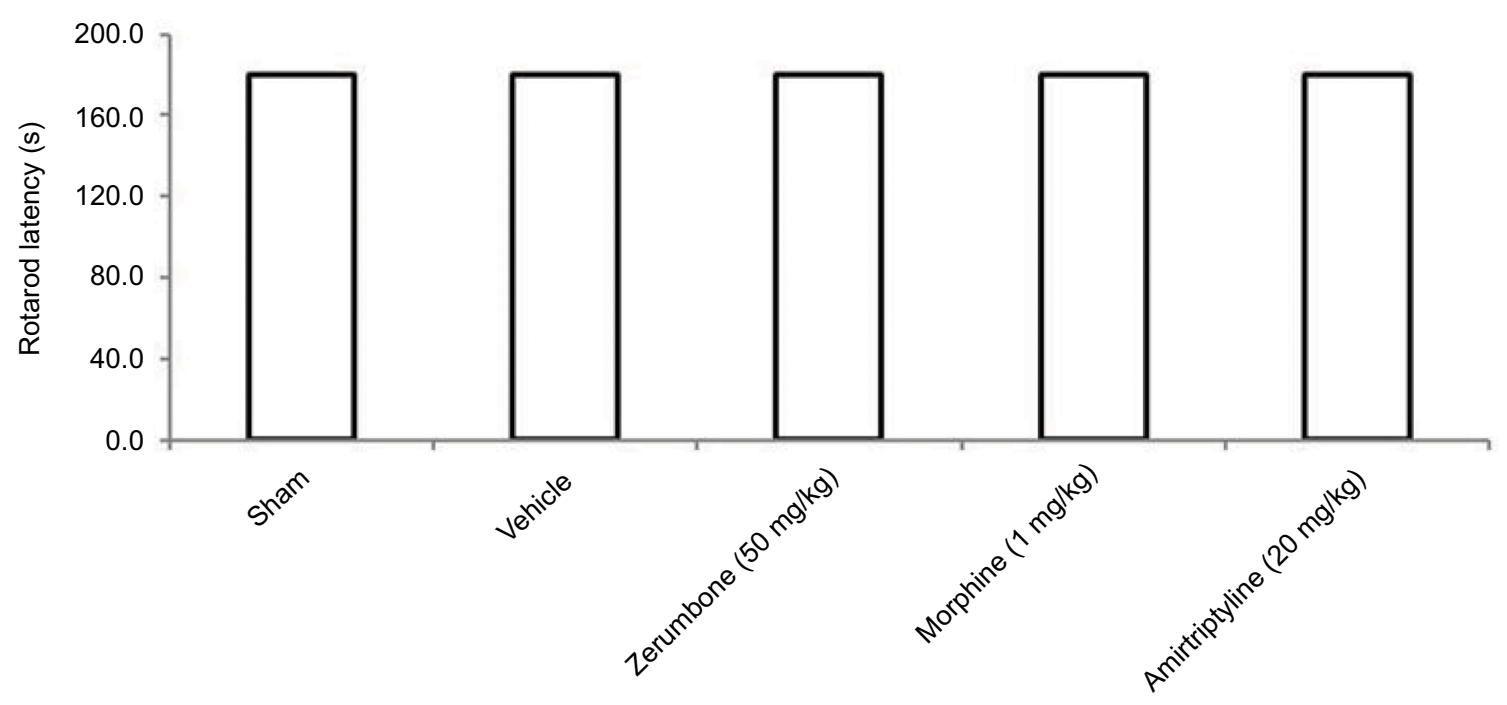

Figure 7 Effect of the treatments on the rotarod performance in $\mathrm{CCl}$ and sham mice. Notes: Data are mean \pm SEM; $n=8$ mice per group.

Abbreviation: $\mathrm{CCl}$, chronic constriction injury.

and inflammation due to nerve injury. TNF- $\alpha$ inhibitors have been reported to reduce peripheral nerve injury-associated thermal and mechanical pain. ${ }^{50}$ Receptor fusion protein, etanercept, and humanized monoclonal antibody, infliximab, are examples of TNF- $\alpha$ inhibitors. Etanercept effectively reduced pain in clinical trials when tested in patients suffering from sciatica and spinal stenosis. ${ }^{51,52}$ Infliximab, on the other hand, benefited patients with L3-L4 and L4-L5 disc herniation. ${ }^{53}$ Furthermore, TNF- $\alpha$ inhibitors are currently used to treat a number of immune disorders including psoriasis, Chrohn's disease, and rheumatoid arthritis. ${ }^{54}$

IL-1 $\beta$ alleviates thermal and mechanical pain hypersensitivity following spinal nerve injury and CCI in mice..$^{55,56}$ Therapeutic targets that are currently approved and used in clinical settings include anakinra and rilonacept, which target IL-1 receptors. Canakinumab is an anti-IL-1 $\beta$ neutralizing antibody used in a few inflammatory diseases such as gout, rheumatoid arthritis, and Still's disease. ${ }^{54}$

IL-6 inhibitors have also been established as therapeutic targets. Tocilizumab, a humanized IL-6 receptor neutralizing antibody, could be used in the treatment of juvenile idiopathic arthritis, rheumatoid arthritis, and sciatica. ${ }^{57}$ Intrathecal injection of anti-IL-6 antibody reduced mechanical allodynia induced by L5 spinal nerve transection. ${ }^{48}$ Furthermore, attenuation and delay of mechanical allodynia were observed in IL-6 knockout mice following sciatic nerve ligation and CCI. ${ }^{58,59}$

Zerumbone's antiinflammatory properties by suppression of these biomarkers have been extensively reflected across various models. Zerumbone administered intravenously successfully downregulates IL- $1 \beta$ expression and attenuates the severity of acute necrotizing pancreatitis induced by sodium taurocholate as well as pancreatitis-induced hepatic injury. ${ }^{60}$ On the other hand, expression of TNF- $\alpha$ was inhibited by intraperitoneal injection of Zer in acute and chronic models of inflammation in mice. ${ }^{27}$ The secretion of serum IL-6 and membrane-bound IL-6 receptors was inhibited by Zer in human cervical cancer and human ovarian cancer cell lines. ${ }^{61}$

Furthermore, oral doses of Zer were able to inhibit TNF- $\alpha$ expression and cytosolic IL-6 in the ultraviolet B photokeratitis and cataractogenesis models. ${ }^{62,63}$ In addition, Zer significantly lowered IL- $1 \beta$ and TNF- $\alpha$ in the colonic mucosa of a dextran sodium sulfate-induced acute ulcerative colitis model. ${ }^{29}$ The p38 MAPK activation of IL-1 $\beta$, IL-6, and TNF- $\alpha$ was decreased by treatment with Zer in a streptozotocin-induced diabetic nephropathy model in rats. ${ }^{64}$ These studies indicate that Zer is involved in the regulation of all these three inflammatory cytokines.

In this study, treatment of Zer from the first day of injury suppressed production of pro-inflammatory mediators as the levels of both the circularity and spinal cord IL- $1 \beta$, TNF- $\alpha$, and IL- 6 were lowered. Upregulated levels of inflammatory cytokines (TNF- $\alpha$ and IL-1 $\beta$ ) trigger the activation and expression of phospholipase- $\mathrm{A}_{2}\left(\mathrm{PLA}_{2}\right)$, an enzyme essential for the initial degradation of myelin sheath after nerve injury. Since the release of these cytokines was suppressed in Zer-treated mice, it was expected 
A

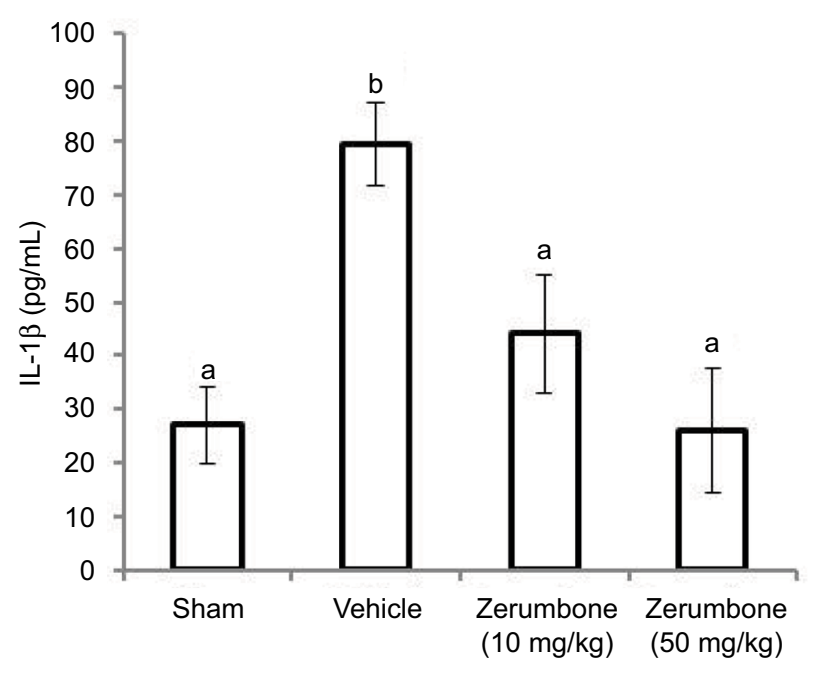

B

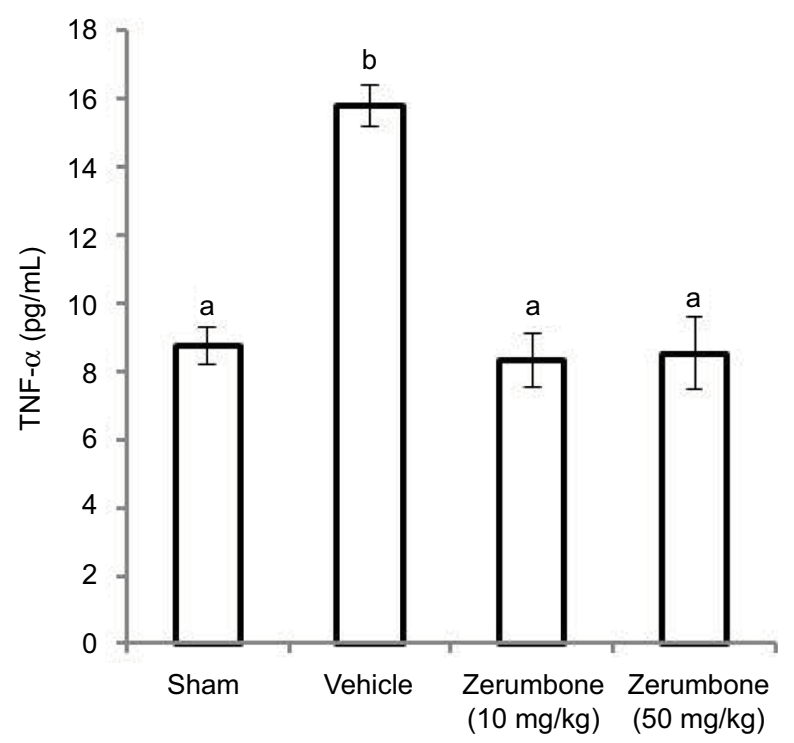

C

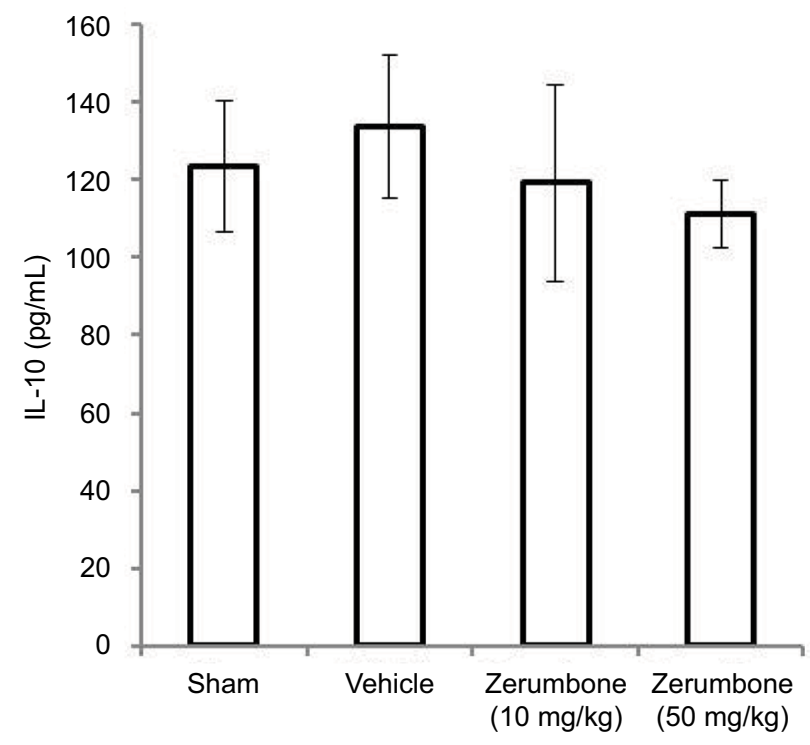

D

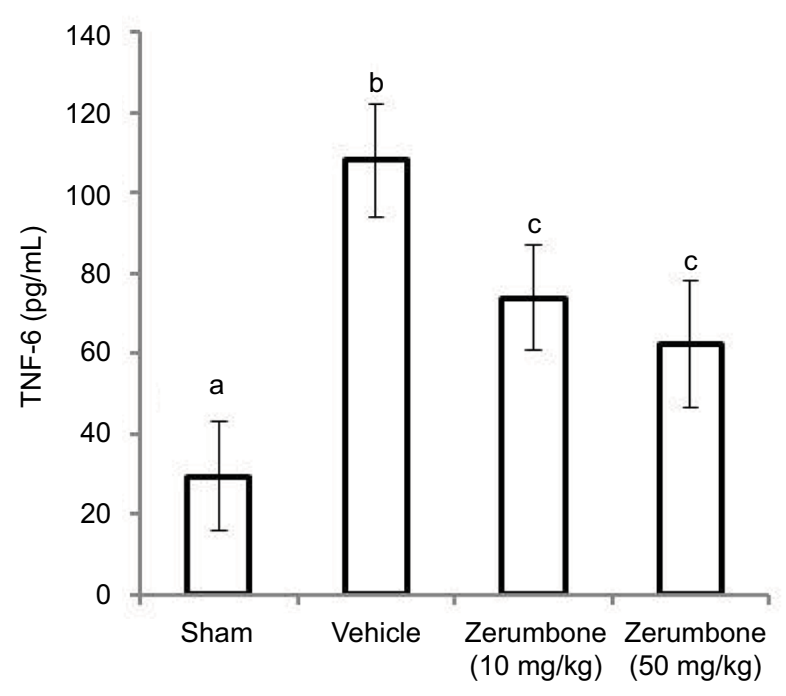

Figure 8 Effect of zerumbone (I0 and $50 \mathrm{mg} / \mathrm{kg}$ ) treatments on the blood plasma levels of (A) IL-I $\beta$, (B) TNF- $\alpha$, (C) IL-I0, and (D) IL-6 in CCI and sham mice. Notes: Values represent mean \pm SEM; $n=6$ mice per group. ${ }^{\text {a.b.c } C o l u m n s ~ w i t h ~ d i f f e r e n t ~ s u p e r s c r i p t s ~ a r e ~ s i g n i f i c a n t l y ~ d i f f e r e n t ~ a t ~} p \leq 0.05$.

Abbreviations: $\mathrm{CCl}$, chronic constriction injury; IL-I $\beta$, interleukin-I beta; TNF- $\alpha$, tumor necrosis factor-alpha.

to stop or at least reduce myelin break down in the sciatic nerve.

The antiinflammatory cytokine, IL-10, however, assumes a role in attenuating the inflammatory process by counterregulating the pro-inflammatory mediator productions and functions while upregulating endogenous anti-cytokines. ${ }^{65}$ IL-10 is usually expressed after the recruitment of macrophages. ${ }^{13}$ Apart from that, IL-10 also plays a protecting role against tissue damage and excessive immune responses. The immune homeostasis is usually maintained by the release of endogenous antiinflammatory cytokines, specifically IL-10, which follows a negative feedback mechanism by suppressing the genes that code pro-inflammatory cytokines and their respective receptors. In addition, IL-10 also has analgesic actions. By evaluating the changes in the production of this cytokine in this study, it would allow clearer understanding of the association of Zer with the inflammatory process that takes place within. ${ }^{66}$

IL-10 was indifferent in this CCI model and Zer-treated groups on day 14 , contrary to earlier reports of peak production of this mediator in the first 2 weeks after injury. ${ }^{65}$ However, there are also reports stating that the expression 

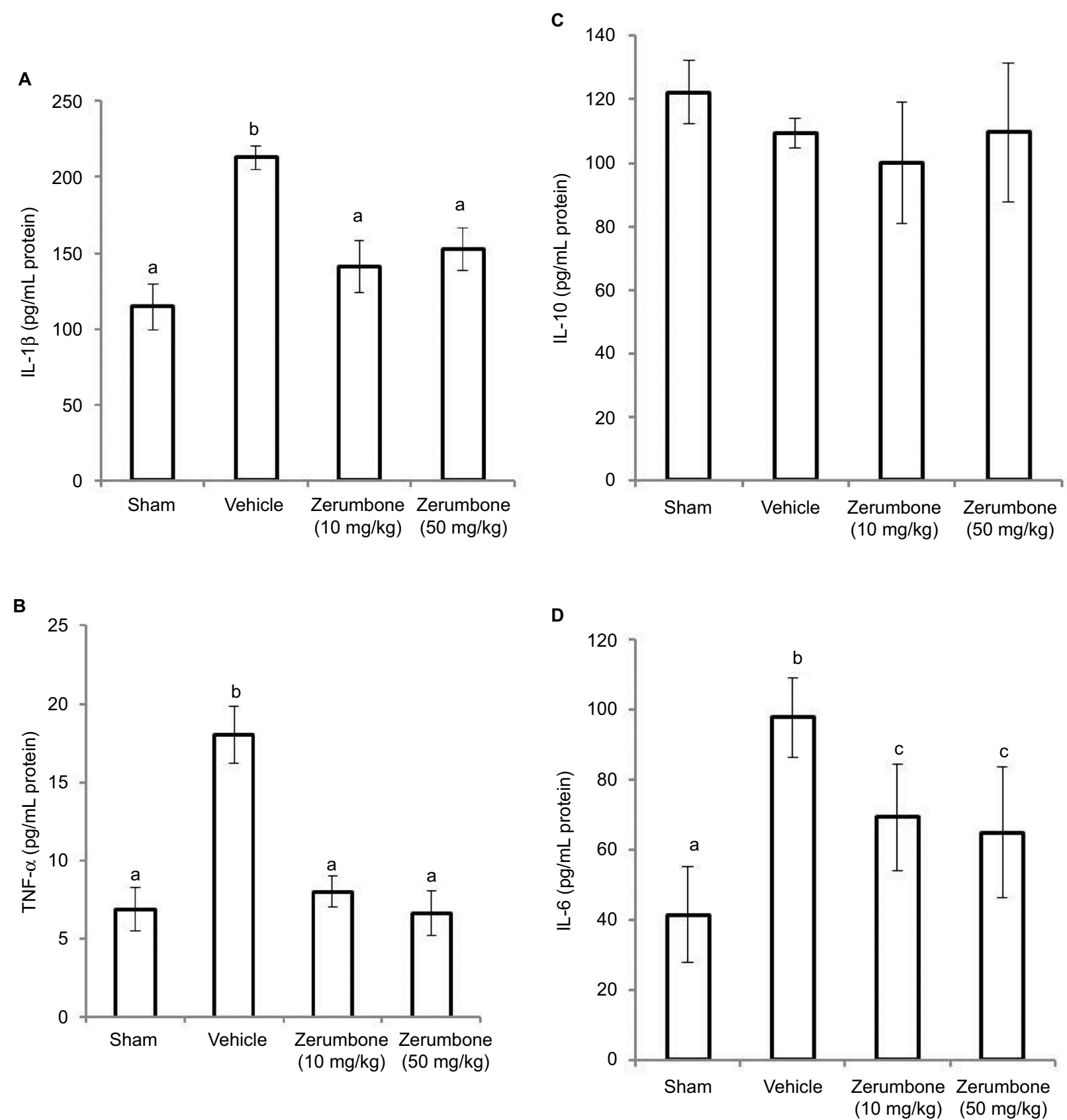

Figure 9 Effect of zerumbone (10 and $50 \mathrm{mg} / \mathrm{kg}$ ) treatment on the L4-L6 spinal cord levels of (A) IL-I $\beta$, (B) TNF- $\alpha$, (C) IL-I0, and (D) IL-6 in CCl and sham mice. Notes: Values represent mean \pm SEM; $n=6$ mice per group. a.b.c Columns with different superscripts are significantly different at $p \leq 0.05$.

Abbreviations: $\mathrm{CCl}$, chronic constriction injury; IL-I $\beta$, interleukin-I beta; TNF- $\alpha$, tumor necrosis factor-alpha.

of this mediator is more gradual and progressive whereby a significant mRNA expression is reached only at day 45 post-injury. ${ }^{67}$

Besides these principal cytokines evaluated in this study, other key components of inflammation such as prostaglandin E2 $\left(\mathrm{PGE}_{2}\right)$, nuclear factor $(\mathrm{NF})-\mathrm{B}$, nitric oxide (NO), and inducible nitric oxide synthase (iNOS) are also involved in peripheral nerve injury. Zerumbone's antiinflammatory effect in many other components of inflammation has been reported in various other models in both in vivo and in vitro. ${ }^{27-29,60,62,68-75}$ Nevertheless, this study is the first report on the antiinflammatory role of Zer in the CCI mouse model of neuropathic pain. Figure 10 represents an overview of Zer's antiinflammatory properties in attenuating allodynia and hyperalgesia.

\section{Conclusion}

In conclusion, Zer was consistent in exhibiting its analgesic properties toward mechanical allodynia, cold allodynia, 
A
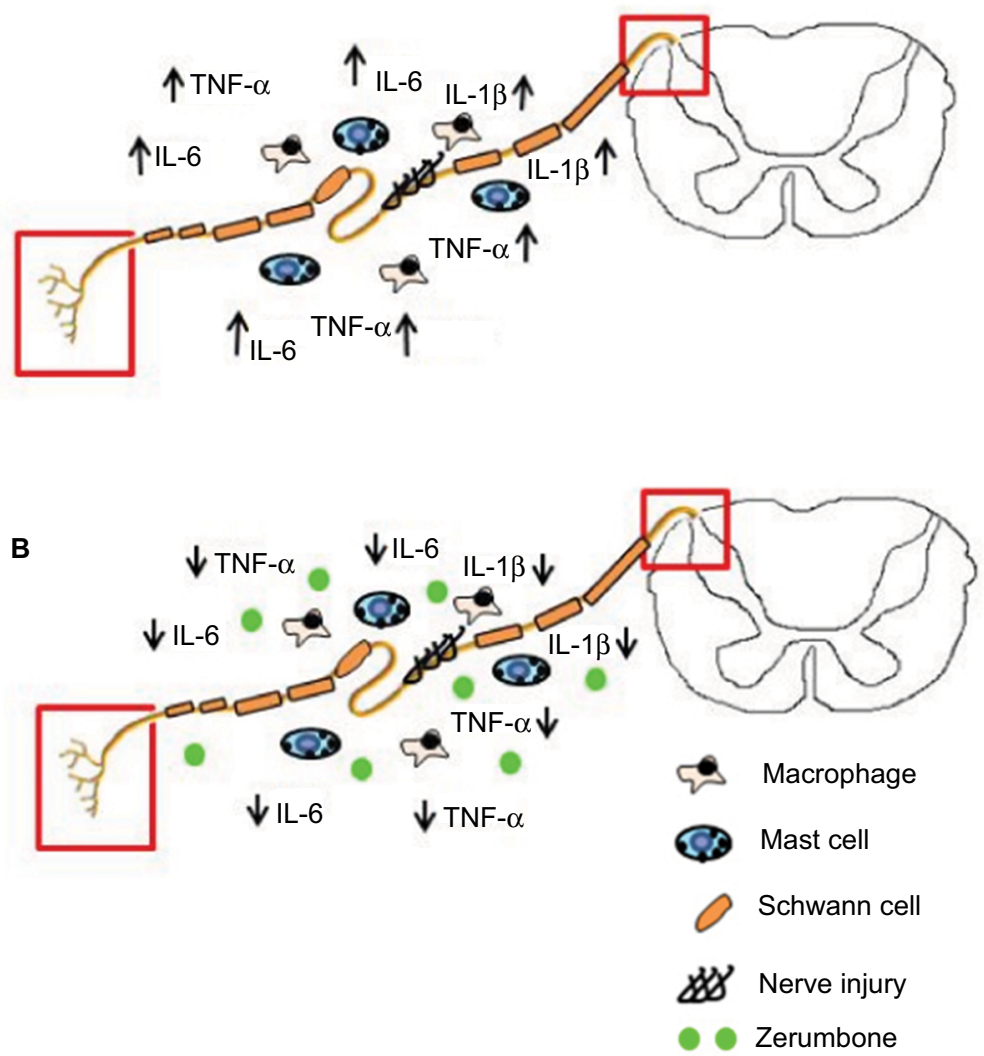

Figure 10 Overview of the antiinflammatory actions of zerumbone on neuropathic pain symptoms allodynia and hyperalgesia.

Notes: (A) In an event of nerve injury, resident and blood-borne macrophages and mast cells rush to the site of injury. These cells release inflammatory mediators such as IL-I $\beta$, TNF- $\alpha$, and IL-6. These mediators cause heightened sensitivity at nociceptor terminals and dorsal horn of spinal cord (red box) leading to behavioral symptoms such as allodynia and hyperalgesia. (B) Treatment of zerumbone lowers the levels of inflammatory mediators (IL-I $\beta$, TNF- $\alpha$, and IL-6) in the blood and spinal cord. This prevents hypersensitivity at nociceptor terminals and dorsal horn of spinal cord (red box) resulting in the attenuation of allodynia and hyperalgesia.

Abbreviations: IL, interleukin; IL-I $\beta$, interleukin-I beta; TNF- $\alpha$, tumor necrosis factor-alpha.

mechanical hyperalgesia, and thermal hyperalgesia when Zer treatment was provided throughout the development and progression of neuropathic pain. This outcome is due to the antiinflammatory property exerted by Zer. We demonstrated that Zer successfully reversed the production of IL-1 $\beta$, IL-6, and TNF- $\alpha$ but not IL-10 in blood plasma as well as in spinal cord tissues. Therefore, Zer is a highly potential drug for the management of pain in neuropathic conditions when administered prophylactically through suppressing the inflammatory event that occurs due to nerve injury.

\section{Acknowledgment}

This research was supported by Universiti Putra Malaysia under the Ministry of Science, Technology \& Innovation, Science Fund Scheme, Grant No: 5450778, which is greatly appreciated.

\section{Authors' contribution}

All authors contributed toward data analysis, drafting and critically revising the paper and agree to be accountable for all aspects of the work.

\section{Disclosure}

The authors report no conflicts of interest in this work.

\section{References}

1. van Hecke O, Austin SK, Khan RA, Smith BH, Torrance N. Neuropathic pain in the general population: a systematic review of epidemiological studies. Pain. 2014;155(4):654-662.

2. Chong MS, Bajwa ZH. Diagnosis and treatment of neuropathic pain. J Pain Symptom Manage. 2003;25(5 Suppl):4-11.

3. Chaudakshetrin P. A survey of patients with neuropathic pain at Siriraj pain clinic. J Med Assoc Thai. 2006;89(3):354-361.

4. Shipton E. Post-surgical neuropathic pain. ANZ J Surg. 2008;78(7): 548-555.

5. Colleoni M, Sacedote P. Murine models of human neuropathic pain. Biochim Biophys Acta. 2010;1802(10):924-933.

6. Boulton AJ, Vinik AI, Arezzo JC, et al. Diabetic neuropathies: a statement by the American Diabetes Association. Diabetes Care. 2005;28(4): 956-962.

7. Treede RD, Jensen TS, Campbell JN, et al. Neuropathic pain: redefinition and a grading system for clinical and research purposes. Neurology. 2008;70(18):1630-1635.

8. Selvarajah D, Cash T, Sankar A, et al. The contributors of emotional distress in painful diabetic neuropathy. Diabetes Vasc Dis Res. 2014;11(4) :218-225.

9. McDiarmid T, Mackler L, Schneider DM. Clinical inquiries. What is the addiction risk associated with tramadol? J Fam Pract. 2005;54(1):72-73. 
10. Daniell HW. Opioid endocrinopathy in women consuming prescribed sustained-action opioids for control of nonmalignant pain. J Pain. 2008;9(1):28-36.

11. Zhang J-M, An J. Cytokines, inflammation and pain. Int Anesthesiol Clin. 2007;45(2):27-37.

12. Austin PJ, Moalem-Taylor G. The neuro-immune balance in neuropathic pain: involvement of inflammatory immune cells, immune-like glial cells and cytokines. J Neuroimmunol. 2010;229(1-2):26-50.

13. Rotshenker S. Wallerian degeneration: the innate-immune response to traumatic nerve injury. J Neuroinflammation. 2011;8:109-109.

14. Fregnan F, Muratori L, Simões AR, Giacobini-Robecchi MG, Raimondo S. Role of inflammatory cytokines in peripheral nerve injury. Neural Regen Res. 2012;7(29):2259-2266.

15. Schafers M, Sorkin L. Effect of cytokines on neuronal excitability. Neurosci Lett. 2008;437(3):188-193.

16. Binshtok AM, Wang H, Zimmermann K, et al. Nociceptors are interleukin-1 $\beta$ sensors. J Neurosci. 2008;28(52):14062-14073.

17. Obreja O, Rathee PK, Lips KS, Distler C, Kress M. IL-1 beta potentiates heat-activated currents in rat sensory neurons: involvement of IL-1RI, tyrosine kinase, and protein kinase C. Faseb J. 2002;16(12): 1497-1503.

18. Pezet S, McMahon SB. Neurotrophins: mediators and modulators of pain. Annu Rev Neurosci. 2006;29:507-538.

19. Sommer C, Kress M. Recent findings on how proinflammatory cytokines cause pain: peripheral mechanisms in inflammatory and neuropathic hyperalgesia. Neurosci Lett. 2004;361(1-3):184-187.

20. Woolf CJ, Mannion RJ. Neuropathic pain: aetiology, symptoms, mechanisms, and management. Lancet (London, England). 1999;353(9168):1959-1964.

21. Moalem G, Tracey DJ. Immune and inflammatory mechanisms in neuropathic pain. Brain Res Rev. 2006;51(2):240-264.

22. Zulazmi NA, Gopalsamy B, Farouk AAO, Sulaiman MR, Bharatham $\mathrm{BH}$, Perimal EK. Antiallodynic and antihyperalgesic effects of zerumbone on a mouse model of chronic constriction injury-induced neuropathic pain. Fitoterapia. 2015;105:215-221.

23. Chia JSM, Omar Farouk AA, Mohamad AS, Sulaiman MR, Perimal EK. Zerumbone alleviates chronic constriction injury-induced allodynia and hyperalgesia through serotonin 5-HT receptors. Biomed Pharmacother. 2016;83:1303-1310.

24. Zulazmi NA, Gopalsamy B, Min JC, et al. Zerumbone alleviates neuropathic pain through the involvement of 1-arginine-nitric oxidecGMP-K(+) ATP channel pathways in chronic constriction injury in mice model. Molecules (Basel, Switzerland). 2017;22(4):E555.

25. Sulaiman MR, Perimal EK, Zakaria ZA, Mokhtar F, Akhtar MN, Lajis NH. Preliminary analysis of the antinociceptive activity of zerumbone. Fitoterapia. 2009;80(4):230-232.

26. Perimal EK, Akhtar MN, Mohamad AS, et al. Zerumbone-induced antinociception: involvement of the L-arginine-nitric oxide-cGMP -PKC-K+ATP channel pathways. Basic Clin Pharmacol Toxicol. 2011;108(3):155-162.

27. Sulaiman MR, Perimal EK, Akhtar MN, et al. Anti-inflammatory effect of zerumbone on acute and chronic inflammation models in mice. Fitoterapia. 2010;81(7):855-858.

28. Thing-Fong T, Shorong-Shii L, Chia Ju C, I-Min L. Zerumbone, a tropical ginger sesquiterpene, ameliorates streptozotocin-induced diabetic nephropathy in rats by reducing the hyperglycemia-induced inflammatory response. Nutrit Metabol. 2013;10(1):64.

29. Murakami A, Hayashi R, Takana T, Kwon KH, Ohigashi H, Safitri R. Suppression of dextran sodium sulfate-induced colitis in mice by zerumbone, a subtropical ginger sesquiterpene, and nimesulide: separately and in combination. Biochem Pharmacol. 2003;66(7):1253-1261.

30. Rahman HS, Rasedee A, Yeap SK, et al. Biomedical properties of a natural dietary plant metabolite, zerumbone, in cancer therapy and chemoprevention trials. BioMed Res Int. 2014;2014:920742.

31. Bennett GJ, Xie YK. A peripheral mononeuropathy in rat that produces disorders of pain sensation like those seen in man. Pain. 1988; 33(1):87-107.
32. Ming-Tatt L, Khalivulla SI, Akhtar MN, et al. Anti-hyperalgesic effect of a benzylidene-cyclohexanone analogue on a mouse model of chronic constriction injury-induced neuropathic pain: participation of the $\kappa$-opioid receptor and K ATP. Pharmacol Biochem Behavior. 2013;114:58-63.

33. Ming-Tatt L, Khalivulla SI, Akhtar MN, et al. Antinociceptive activity of a synthetic curcuminoid analogue, 2, 6-bis-(4-hydroxy-3-methoxybenzylidene) cyclohexanone, on nociception-induced models in mice. Basic Clin Pharmacol Toxicol. 2012;110(3):275-282.

34. Chaplan SR, Bach FW, Pogrel JW, Chung JM, Yaksh TL. Quantitative assessment of tactile allodynia in the rat paw. J Neurosci Methods. 1994;53(1):55-63.

35. Campana G, Rimondini R. Mechanical nociception measurement in mice and rats with automated von Frey equipment. In: Spampinato SM, editor. Opioid Receptors: Methods and Protocols. New York, NY: Springer; 2015:229-231.

36. Nadal X, Banos JE, Kieffer BL, Maldonado R. Neuropathic pain is enhanced in delta-opioid receptor knockout mice. Eur J Neurosci. 2006;23(3):830-834.

37. Hargreaves K, Dubner R, Brown F, Flores C, Joris J. A new and sensitive method for measuring thermal nociception in cutaneous hyperalgesia. Pain. 1988;32(1):77-88.

38. Randall LO, Selitto JJ. A method for measurement of analgesic activity on inflamed tissue. Arch Int Pharmacodyn. 1957;111(4):409-419.

39. Beirowski B, Adalbert R, Wagner D, et al. The progressive nature of Wallerian degeneration in wild-type and slow Wallerian degeneration (WldS) nerves. BMC Neurosci. 2005;6:6.

40. Chen L, Chen W, Qian X, Fang Y, Zhu N. Liquiritigenin alleviates mechanical and cold hyperalgesia in a rat neuropathic pain model. Sci Rep. 2014;4(5676):1-4.

41. Costa B, Comelli F, Bettoni I, Colleoni M, Giagnoni G. The endogenous fatty acid amide, palmitoylethanolamide, has anti-allodynic and antihyperalgesic effects in a murine model of neuropathic pain: involvement of CB1, TRPV1 and PPAR $\gamma$ receptors and neurotrophic factors. Pain. 2008;139(3):541-550.

42. Guneli E, Onal A, Ates M, et al. Effects of repeated administered ghrelin on chronic constriction injury of the sciatic nerve in rats. Neurosci Lett. 2010;479:226-230.

43. Wells MR, Racis SP, Jr., Vaidya U. Changes in plasma cytokines associated with peripheral nerve injury. J Neuroimmunol. 1992;39(3):261-268.

44. Perrin FE, Lacroix S, Avilés-Trigueros M, David S. Involvement of monocyte chemoattractant protein-1, macrophage inflammatory protein- $1 \alpha$ and interleukin- $1 \beta$ in Wallerian degeneration. Brain. 2005;128(4):854-866.

45. Sacerdote P, Franchi S, Trovato AE, Valsecchi AE, Panerai AE, Colleoni M. Transient early expression of TNF-alpha in sciatic nerve and dorsal root ganglia in a mouse model of painful peripheral neuropathy. Neurosci Lett. 2008;436(2):210-213.

46. Dubovy P, Jancalek R, Klusakova I, Svizenska I, Pejchalova K. Intra- and extraneuronal changes of immunofluorescence staining for TNF-alpha and TNFR1 in the dorsal root ganglia of rat peripheral neuropathic pain models. Cell Mol Neurobiol. 2006;26(7-8):1205-1217.

47. DeLeo JA, Colburn RW, Nichols M, Malhotra A. Interleukin-6-mediated hyperalgesia/allodynia and increased spinal IL-6 expression in a rat mononeuropathy model. J Interferon Cytokine Res. 1996;16(9):695-700.

48. Arruda JL, Colburn RW, Rickman AJ, Rutkowski MD, DeLeo JA. Increase of interleukin- 6 mRNA in the spinal cord following peripheral nerve injury in the rat: potential role of IL-6 in neuropathic pain. Brain Res Mol Brain Res. 1998;62(2):228-235.

49. Whitehead KJ, Smith CG, Delaney SA, et al. Dynamic regulation of spinal pro-inflammatory cytokine release in the rat in vivo following peripheral nerve injury. Brain Behav Immun. 2010;24(4):569-576.

50. Iwatsuki K, Arai $\mathrm{T}$, Ota $\mathrm{H}$, et al. Targeting anti-inflammatory treatment can ameliorate injury-induced neuropathic pain. PloS One. 2013;8(2): e57721.

51. Genevay S, Stingelin S, Gabay C. Efficacy of etanercept in the treatment of acute, severe sciatica: a pilot study. Ann Rheum Dis. 2004;63(9): $1120-1123$. 
52. Ohtori S, Miyagi M, Eguchi Y, et al. Epidural administration of spinal nerves with the tumor necrosis factor-alpha inhibitor, etanercept, compared with dexamethasone for treatment of sciatica in patients with lumbar spinal stenosis: a prospective randomized study. Spine. 2012;37(6):439-444.

53. Korhonen T, Karppinen J, Paimela L, et al. The treatment of discherniation-induced sciatica with infliximab: one-year follow-up results of FIRST II, a randomized controlled trial. Spine. 2006;31(24):2759-2766.

54. Lees JG, Duffy SS, Moalem-Taylor G. Immunotherapy targeting cytokines in neuropathic pain. Front Pharmacol. 2013;4:142.

55. Wolf G, Gabay E, Tal M, Yirmiya R, Shavit Y. Genetic impairment of interleukin-1 signaling attenuates neuropathic pain, autotomy, and spontaneous ectopic neuronal activity, following nerve injury in mice. Pain. 2006;120(3):315-324.

56. Sommer C, Petrausch S, Lindenlaub T, Toyka KV. Neutralizing antibodies to interleukin 1-receptor reduce pain associated behavior in mice with experimental neuropathy. Neurosci Lett. 1999;270(1):25-28.

57. Ohtori S, Miyagi M, Eguchi Y, et al. Efficacy of epidural administration of anti-interleukin-6 receptor antibody onto spinal nerve for treatment of sciatica. Eur Spine J. 2012;21(10):2079-2084.

58. Ramer MS, Murphy PG, Richardson PM, Bisby MA. Spinal nerve lesion-induced mechanoallodynia and adrenergic sprouting in sensory ganglia are attenuated in interleukin-6 knockout mice. Pain. 1998;78(2):115-121.

59. Murphy PG, Ramer MS, Borthwick L, Gauldie J, Richardson PM, Bisby MA. Endogenous interleukin-6 contributes to hypersensitivity to cutaneous stimuli and changes in neuropeptides associated with chronic nerve constriction in mice. Eur J Neurosci. 1999;11(7): 2243-2253.

60. Wenhong D, Jia Y, Weixing W, et al. Zerumbone attenuates the severity of acute necrotizing pancreatitis and pancreatitis-induced hepatic injury. Mediators Inflammation. 2012;2012:12.

61. Abdelwahab SI, Abdul AB, Zain ZNM, Hadi AHA. Zerumbone inhibits interleukin- 6 and induces apoptosis and cell cycle arrest in ovarian and cervical cancer cells. Int Immunopharmacol. 2012;12(4):594-602.

62. Chen BY, Lin DP, Su KC, et al. Dietary zerumbone prevents against ultraviolet B-induced cataractogenesis in the mouse. Mol Vis. 2011;17: 723-730.

63. Chen BY, Lin DP, Wu CY, et al. Dietary zerumbone prevents mouse cornea from UVB-induced photokeratitis through inhibition of NFkappaB, iNOS, and TNF-alpha expression and reduction of MDA accumulation. Mol Vis. 2011;17:854-863.
64. Tzeng TF, Liou SS, Chang CJ, Liu IM. The ethanol extract of Zingiber zerumbet attenuates streptozotocin-induced diabetic nephropathy in rats. Evidence Based Complementary Altern Med. 2013;2013:340645.

65. Siqueira Mietto B, Kroner A, Girolami EI, Santos-Nogueira E, Zhang J, David S. Role of IL-10 in resolution of inflammation and functional recovery after peripheral nerve injury. $J$ Neurosci. 2015;35(50):16431-16442.

66. Oliveira Júnior JOd, Portella Junior CSA, Cohen CP. Inflammatory mediators of neuropathic pain. Revista Dor. 2016;17(Suppl 1):35-42.

67. Okamoto K, Martin DP, Schmelzer JD, Mitsui Y, Low PA. Pro- and anti-inflammatory cytokine gene expression in rat sciatic nerve chronic constriction injury model of neuropathic pain. Exp Neurol. 2001;169(2):386-391.

68. Murakami A, Takahashi D, Kinoshita T, Koshimizu K, Kim H, W., Yoshihiro A. Zerumbone, a Southeast Asian ginger sesquiterpene, markedly suppresses free radical generation, proinflammatory protein production, and cancer cell proliferation accompanied by apoptosis: the a,b-unsaturated carbonyl group is a prerequisite. Carcinogenesis. 2002;23(5):795-802.

69. Szabolcs A, Tiszlavicz L, Kaszaki Jea. "Zerumbone exerts a beneficial effect on inflammatory parameters of cholecystokinin octapeptideinduced experimental pancreatitis but fails to improve histology. Pancreas. 2007;35(3):249-255.

70. Al-Saffar FJ, Ganabadi S, Fakurazi S, Yaakub H, Lip M. Chondroprotective effect of zerumbone on monosodium iodoacetate induced osteoarthritis in rats. J Appl Sci. 2010;10(4):248-260.

71. Al-Saffar FJ, Ganabadi S, Fakurazi S, Yaakub H. Zerumbone significantly improved immunoreactivity in the synovium compared to Channa striatus extract in monosodium iodoacetate (MIA)-induced knee osteoarthritis in rat. J Med Plants Res. 2011;5(9):1701-1710.

72. Somchit MN, Mak JH, Bustamam AA, et al. Zerumbone isolated from Zingiber zerumbet inhibits inflammation and pain in rats. $J$ Med Plants Res. 2012;6(2):177-180.

73. Ganabadi S, Kadir SFA. Zerumbone's effect on major histocompatibility complex type II cells in synovial membrane of osteoarthritic joint. Res J Vet Sci. 2009;2(1):14-20.

74. Zakaria ZA, Mohamad AS, Chear CT, Wong YY, Israf DA, Sulaiman MR. Antiinflammatory and antinociceptive activities of Zingiber zerumbet methanol extract in experimental model systems. Med Princ Pract. 2010;19(4):287-294.

75. Chien TY, Huang SKH, Lee CJ, Tsai PW, Wang CC. Antinociceptive and anti-inflammatory effects of zerumbone against mono-iodoacetateinduced arthritis. Int J Mol Sci. 2016;17(2):249.
Journal of Pain Research

\section{Publish your work in this journal}

The Journal of Pain Research is an international, peer reviewed, open access, online journal that welcomes laboratory and clinical findings in the fields of pain research and the prevention and management of pain. Original research, reviews, symposium reports, hypothesis formation and commentaries are all considered for publication

\section{Dovepress}

The manuscript management system is completely online and includes a very quick and fair peer-review system, which is all easy to use. Visit http://www.dovepress.com/testimonials.php to read real quotes from published authors. 